\title{
Molecules, Fossils, and the Origin of Tetrapods
}

\author{
Axel Meyer and Sarah I. Dolven \\ Department of Ecology and Evolution, State University of New York, Stony Brook, NY 11794, USA
}

Summary. Since the discovery of the coelacanth, Latimeria chalumnae, more than 50 years ago, paleontologists and comparative morphologists have debated whether coelacanths or lungfishes, two groups of lobe-finned fishes, are the closest living relatives of land vertebrates (Tetrapoda). Previously, Meyer and Wilson (1990) determined partial DNA sequences from two conservative mitochondrial genes and found support for a close relationship of lungfishes to tetrapods. We present additional DNA sequences from the $12 \mathrm{~S}$ rRNA mitochondrial gene for three species of the two lineages of lungfishes that were not represented in the first study: Protopterus annectens and Protopterus aethiopicus from Africa and Neoceratodus forsteri (kindly provided by B. Hedges and L. Maxson) from Australia. This extended data set tends to group the two lepidosirenid lungfish lineages (Lepidosiren and Protopterus) with Neoceratodus as their sister group. All lungfishes seem to be more closely related to tetrapods than the coelacanth is. This result appears to rule out the possibility that the coelacanth lineage gave rise to land vertebrates. The common ancestor of lungfishes and tetrapods might have possessed multiple morphological traits that are shared by lungfishes and tetrapods [Meyer and Wilson (1990) listed 14 such traits]. Those traits that seem to link Latimeria and tetrapods are arguably due to convergent evolution or reversals and not to common descent. In this way, the molecular tree facilitates an evolutionary interpretation of the morphological differences among the living forms. We recommended that the extinct groups of lobe-finned fishes be placed onto the molecular tree that has lungfishes and not the coelacanth more closely related to tetrapods. The placement of fossils would help to fur-

Offprint requests to: Axel Meyer ther interpret the sequence of morphological events and innovations associated with the origin of tetrapods but appears to be problematic because the quality of fossils is not always high enough, and differences among paleontologists in the interpretation of the fossils have stood in the way of a consensus opinion for the branching order among lobefinned fishes. Marshall and Schultze (1992) criticized the morphological analysis presented by Meyer and Wilson (1990) and suggest that 13 of the 14 morphological traits that support the sister group relationship of lungfishes and tetrapods are not shared derived characters. Here we present further alternative viewpoints to the ones of Marshall and Schultze (1992) from the paleontological literature. We argue that all available information (paleontological, neontological, and molecular data) and rigorous cladistic methodology should be used when relating fossils and extant taxa in a phylogenetic framework.

Key words: Polymerase chain reaction - 12S rRNA - Coelacanth - Latimeria chalumnae Ray-finned fishes - Lungfishes - Lepidosiren Protopterus - Neoceratodus - Conquest of land Vertebrate phylogeny

\section{Introduction}

The origin of tetrapods is a problem of obvious importance. To understand the evolutionary sequence of morphological events and innovations that facilitated the conquest of land, it is essential to determine the phylogenetic relationships among the living as well as the extinct representatives of the groups involved. The evolutionary relationships of lungfishes to tetrapods have been in dispute since 

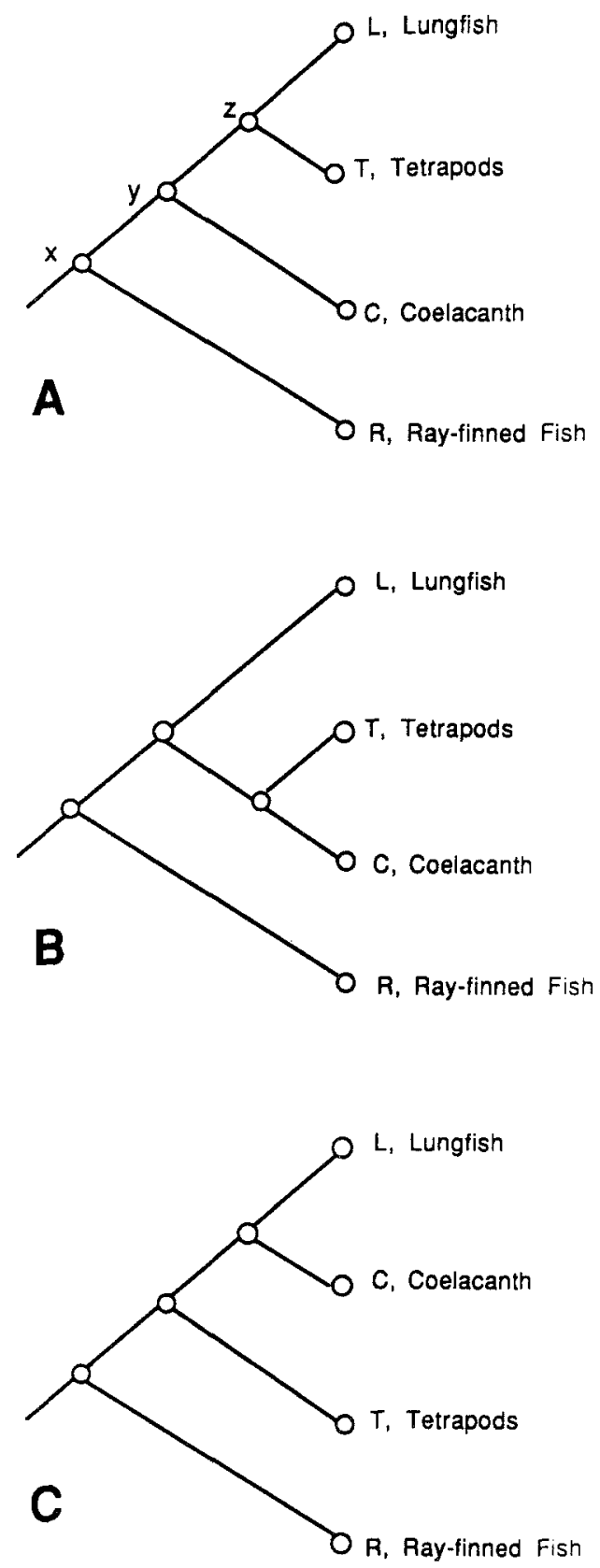

Fig. 1. Phylogenetic relationships of the major groups of living bony fishes (Osteichthyes) to one another. A Tree relating the ray-finned fishes (R: Actinopterygii) and the three groups of lobefinned fishes (Sarcopterygii): coelacanths (also called Actinistia: C), lungfishes (Dipnoi: L), and tetrapods (T). In this tree $x$ refers to the ancestor of all groups and $y$ to the common ancestor of all lobe-finned fishes. The terminology: $z \mathrm{~L}$ is the lungfish lineage, $y \mathrm{C}$ is the coelacanth lineage, $z \mathrm{~T}$ is the tetrapod lineage, and $x \mathrm{R}$ is the ray-finned fish lineage. B A tree that relates tetrapods and coelacanths more closely and places lungfish as the sister group of all sarcopterygians in agreement with Schultze (1987). C Tree relating coelacanths and lungfishes as the sister group of tetrapods. The morphological data presented in Table 2 of Meyer and Wilson (1990) when analyzed with parsimony PAUP (Swofford 1991) favor tree $A(T L=30, C I=0.73$ ) over alternatives $B$ ( $T L$ $=43, \mathrm{CI}=0.51)$ and $\mathrm{C}(\mathrm{TL}=37, \mathrm{CI}=0.59)$. their discovery more than 100 years ago (see Patterson 1980; Rosen et al. 1981 for historical perspectives on the problem); they have variously been considered to be related to actinistians (i.e., coelacanths), tetrapods, actinopterygians (ray-finned fishes), or crossopterygians (an unnatural group combining coelacanths and rhipidistian fishes) (Fig. 1) (reviewed by Forey 1988). Since the sensational discovery of the "living fossil," Latimeria chalumnae (Smith 1939, 1953; reviewed in Thomson 1991) it has become the favorite closest living relative of tetrapods. Almost all biology texts (e.g., Romer 1966) and the majority of publications in the primary literature seem to support coelacanths over lungfishes. However, there is by no means universal agreement in the vast literature on this point (e.g., Wahlert 1968; Lovtrup 1977; Wiley 1979; Forey 1980, 1987; Rosen et al. 1981; Lagios 1982; Fritzsch 1987; Northcutt 1987; Schultze 1987; reviewed by Forey 1988; Gee 1990). Without certainty about the branching patterns linking the living groups (much less the extinct groups), it remained difficult to develop a detailed model of how fishes conquered land.

\section{The Contribution of Molecular Data}

Meyer and Wilson (1990) sequenced 664 bp of two slowly evolving mitochondrial genes (12S rRNA and cytochrome $b$ ) from three species - a ray-finned fish (Cichlasoma citrinellum), a South American lungfish (Lepidosiren paradoxa), and the coelacanth ( $L$. chalumnae)-and compared them to the published sequences of tetrapod mitochondrial DNA (mtDNA), e.g., for the frog Xenopus laevis (Roe et al. 1985). We concluded, with statistical confidence (Felsenstein 1985) that the lungfishes and not the coelacanth are the closest living relative of tetrapods (Fig. 1A). Because paleontologists had not agreed on the branching order among the living groups, much less the extinct taxa, we regarded it as a worthwhile contribution to present a statistically supported branching pattern for the living groups derived from a molecular data set. Only after a best estimate of branching pattern is achieved can we hope to retrace character evolution and gain an improved understanding of the conquest of land.

Previous molecular analyses did not settle the issue because they did not include a lungfish (Maeda et al. 1984; Hillis and Dixon 1989). Since our initial study (Meyer and Wilson 1990), additional molecular data have been published (Gorr et al. 1991; Stock et al. 1991) but could not resolve the branching order because of the inadequacy of the molecule or the methods of phylogenetic reconstruction chosen (Meyer and Wilson 1991; Sharp et al. 1991; Stock and Swofford 1991).

Normark et al. (1991) collected additional 
mtDNA sequences for a shorter piece of cytochrome $b$ [and inferred 97 amino acids (AA)] than was gathered by Meyer and Wilson (1990), for several fishes and for another lungfish lineage, the African Protopterus spec. They further determined mtDNA sequences coding for up to $159 \mathrm{AA}$ of the mitochondrial cytochrome oxidase I and up to $73 \mathrm{AA}$ for the mitochondrial cytochrome oxidase II genes in several fishes. The DNA sequences of the coelacanth, Latimeria, or any lungfish were not determined by them for these two additional genes, therefore only their new cytochrome $b$ sequences for Protopterus are relevant to the issue at hand. Normark et al.'s (1991) cytochrome $b$ data support the lungfish-tetrapod sister group relationship by a bootstrap value of $51 \%$. Reasons for Normark et al.'s (1991) lower level of support than the one previously reported by Meyer and Wilson (1990) are several. Normark et al. (1991) sequenced a smaller piece of cytochrome $b$; they did not sequence the $12 \mathrm{~S}$ gene and did not include it into their analysis; they hence had fewer phylogenetically informative sites than Meyer and Wilson (1990) to investigate the coelacanthlungfish-tetrapod question. We (Meyer and Wilson 1990) found the 12S rRNA gene to contain a higher density of phylogenetically informative sites (17 of 240 ) than the cytochrome $b$ gene (16 of 360) for the taxa included in our analysis. The number of phylogenetically informative sites will partly depend on the number of taxa included in the analysis. Normark et al. (1991) included a larger number of taxa in their analysis than we (Meyer and Wilson 1990) did. Sanderson and Donoghue (1989) showed that homoplasy increases, and the consistency index of data decreases, with the number of taxa in an analysis. This is probably because the probability of character-state changes increases with the total number of branches on a tree, given that there are only four states in DNA sequences. Normark et al. (1991) presented support for the lungfish-tetrapod relationship and confirmed our finding that mtDNA can be used for "deep" phylogenetic questions, not only for population-level work and relationships among closely related species.

The molecular support for the lungfish-tetrapod sister group relationship suggested that their common stem might be longer than had been believed based on paleontological data. If this finding is correct, it could mean that the common lineage of lungfishes and tetrapods is longer or, alternatively, suggests a closer link between coelacanths and actinopterygian fossils than previously thought. This difference between molecular data and current paleontological understanding could be resolved in several ways but will probably have to await further discovery or reinterpretation of Devonian sarcopterygian fossils.
Based on our molecular tree, Meyer and Wilson (1990) addressed the question of whether the character states of morphological traits in the extant taxa under consideration represent shared derived traits (synapomorphies) or homoplasies. Meyer and Wilson (1990) concluded that 14 of 22 phylogenetically informative characters taken from the literature (compiled by Prof. Peter Forey) also support the branching pattern based on our molecular results (Fig. 1). In agreement with the parsimony principle these 14 traits were interpreted to be shared derived characters of lungfish and tetrapods that arose along the $y z$ lineage (Fig. 1A), whereas the other eight characters required more than one character change to fit the most parsimonious molecular and morphological tree.

\section{Limitations of Molecular Data}

Because molecular data can only be collected from living groups, Meyer and Wilson (1990, p. 363) postulated that the extinct groups of sarcopterygian fishes should be fit in the phylogeny that links lungfishes as the closest living relatives of tetrapods to the exclusion of Latimeria.

Only once a most parsimonious phylogeny of living as well as extinct groups is well established, can characters be traced back along that cladogram. Because much debate among paleontologists and comparative biologists had not led to a generally accepted phylogeny, we did not feel confident to extend our molecular phylogeny into the uncharted waters of extinct fishes. Morphological character states of the lungfish-tetrapod clade interpreted (by Meyer and Wilson 1990) to be synapomorphies among the living lobe-finned fishes may turn out to be homoplasious if the fossils are placed onto the molecular branching pattern.

The contribution of Marshall and Schultze (1992) is welcome in this regard. They stress the importance of fossils in the study of the origin of vertebrates and question Meyer and Wilson's (1990) interpretation of 14 traits as synapomorphies between lungfish and tetrapods, arguing that 13 of these traits were incorrectly interpreted by us. Before the criticisms of Marshall and Schultze (1992) are addressed, new molecular data and further analyses for all the lungfish lineages that were not represented in the first study (Protopterus from Africa and NeOceratodus from Australia) will be presented.

\section{Materials and Methods}

Partial DNA sequences of the mitochondrial 12S rRNA gene were determined from the Midas cichlid fish [C. citrinellum, 
Iepidosiren ---AGG-ACTACTAGCACAAGCTAAAAACTCAAAGGACTTGGCGGTGCCTCAAACCCACCTAGAGGAGCCTGTCCTAAAACCGATAATC Protopterus 1 CGCCAGGAACTACAAGCCCAAGCTIAAAACCCAAAGGACTTGGCGGTGCCTCACACCCACCTAGAGGAGCCTGTTCTAGAACCGATAATC Protopterus2 CCCCAGGAACTACAAGCCCAGGCTTAAAACCCAAAGGACTTGGCGGTGCCTCACACCCACCTAGAGGAGCCTGTTCTAGAACCGATAATC Neoceratodus --..-- AGCTTAAAACCCAAAGGACTTGGCGGTGCCTCACACCCACCTAGAGGAGCCTGTTCTAGAACCGATAATC Frog CGCCAG-AACTACGAGCCTAAGCTTAAAACCCAAAGGACTTGGCGGTGCTCCAAACCCACCTAGAGGAGCCTGTTCTGTAATCGATACCC Latimeria ----GGAACAACAAGCCACAGCTIAAAACTCAAAGGACTTGGCGGTGCTTCATACCCCC-TAGAGGAGCCTGTTCTAGAACCGATAAAC Ray-Finned ----GGAACTACGAGCATTAGCTTAAAACCCAAAGGACTTGGCGGTGCTITAGACCCCCCTAGAGGAGCCTGTICTAGAACCGATAATC

Lepidosiren CACGTWITACCTAACCACTPTPTGCCAATTCAGCCTATATACCGCCGTCGCCAGCCAACCCCGTAGAGAAATAAAGTAGGCAAAATTAA Protopterus 1 CACGITTTACCCAACC-T"TCCCTGGCATTTCAGCCTATATACCGCCGTCGCCAGCCAACCCCCTGAGGCCCACT-AGPTGGCAAAATAGA protopterus 2 CACGITACCCAACC-TTCCCTGGCATTTCAGCCTATATACCGCCGTCGCCAGCCAACCCCCTGAGGCCCACT-AGTTGGCAAAATAGA Neoceratodus CACGTTAAACCTCACCGCTTCTTGCCACTACCGTCTATATACCACCGTCGCCAGCTITACCCCGTGAGGGTGAAAAAGTAAGCACAATTGG Frog Latimeria CTCGCTAAACCTCACCACTTCTTGCCAAACCCGCCTATATACCACCGTCGCCAGCCCACCTCGTGAGAGATTCITAGTAGGCITAATGAT CCCGATCAACCTCAACCACACTTGCTATTTCAGCCTATATACCGCCGTCGCCAGCCCACCCTGTGAAGGAAATACAATGGGCAAAAATAA Ray-Finned CCCGTTAAACCTCACCCTCCCTTGTCATCCCCGCCTATATACCGCCGTCGTCAGCTTACCCTGTGAAGGCACTATAGTAAGCAAAACTAG

Lepidosiren CTTAGTTAAATACGTCAGGTCGAGGTGTAGCATATGAAGTGGGAAGAGATGGGCTACATTITCTTG-- -TAGAATA-TACGAATAGC-T protopterus 1 TAGCATCTAACACGTCAGGTCGAGGTGAGCACATGGGAGGGAA-GAAATGGGCTACATTITCTAA---TAGAAAA-CACGGACAA-CC Protopterus2 TAACATCTAACACGTCAGGTCGAGGTGTAGCACATGAGAAGGAA-GAAATGGGCTACATIITCTGA----TAGAAAA-CACGGA----- Neoceratodus TACAACCAAAAACGTCAGGTCGAGGTGTAGCGAATGAAGCGGAAAGAAATGGGCTACATTITCTA-TAAAAGAATA-TACGAAAGAC-C Frog Latimeria TITTCATCAACACGTCAGGTCAAGGTGTAGCATATGAAGTGGGAAGAAATGGGCTACATTITCTATACCTTAGAATA-AACGAAAGATCT Ray-Finned TAAAACCCAAAACGCCAGGTCGAGGTGTAGCATATGAGAGGGAAAGAAATGGGCTACATTCCCTA--CTTPAGGGAA-CACGGATAAT-G

Lepidosiren AAATGAAA--TAAAGCTG-GAAGGT-GITTAGAAGAAA-_..................

Protopterus 1 CCATGAAA--TTGGGGTITTAAGCTGGATTTAGTAGTAAGAAAA--.-.-.-.-.--

Protopterus2

Neoceratodus TAATGAAA---CAAAGTCAGAAGGTGGATTTAGCAGTAAGAAAAACCAAGAATATITITCT

Frog CTATGAAACCAGATCGAGAAAAGGCGGATTIAGCAGTAAAGAGAAACAAGAGAGTTCCTCT

Latimeria CAGCGAAA-CCTGIACITIGAAGGAGGATTTAGCAGTAAAAGGGGAATAGAGAGCCCCTCT

Ray-Finned TAATGAAAA--GTACATIAGAAGGAGGATTTAGCAGTAAGCAAAA-ATAGAGGCA------

Fig. 2. Sequences of parts of the mitochondrial 12S rRNA gene. The sequences shown correspond about to positions $2547-2875$ for $12 \mathrm{~S}$ rRNA in the frog mtDNA sequence (Roe et al. 1985). Dashes indicate proposed indels (and at the end missing data). Protopterus 1 is $P$. annectens and 2 is $P$. aethiopicus. At the positions at which deletions or additions occurred, alternative alignments cannot be ruled out completely. The asterisk at position 245 indicates the position up to which data were included in the phylogenetic analysis; to the right of it the alignment is less certain and data were excluded from the analysis.

Actinopterygii (ray-finned fish)], the three lineages of lungfishes [L. paradoxa (South America), Protopterus annectens and Protopterus aethiopicus (Africa)] and the coelacanth (L. chalumnae). The partial 12S sequence of the Australian lungfish Neoceratodus forsteri was kindly provided by B. Hedges and L. Maxson. DNA was extracted, amplified via the polymerase chain reaction (PCR), and directly sequenced as described by Kocher et al. (1989) and Meyer et al. (1990) using tissues from frozen specimens. The data from some of these species had been previously published (Meyer and Wilson 1990); for this study the sequences for two additional genera of lungfishes (Protopterus and Neoceratodus) were added. A shorter $12 \mathrm{~S}$ sequence of Neoceratodus than reported here had been determined from a formalin-fixed specimen by A.M.

Amplifications and Direct Sequencing. Amplifications were done in $25 \mu 1$ of Tris ( $67 \mathrm{mM}, \mathrm{pH} 8.8)$ containing $2 \mathrm{mM} \mathrm{MgCl}_{2}$, $1 \mathrm{mM}$ of each dNTP, $1 \mu \mathrm{M}$ of each primer, template DNA (10$1000 \mathrm{ng}$ ), and Taq polymerase (1.25 units, Perkin-Elmer-Cetus). The primer sequences for the PCR amplification of the partial $12 S$ rRNA are L1091 (5'-AAAAAGCTTCAAACTGGGATTAGATACCCCACTAT-3') and H1478 (5'-TGACTGCAGAGGGTGACGGGCGGTGTGT-3') (Kocher et al. 1989). L and $\mathrm{H}$ refer to the light and heavy strands, respectively, and the numbers refer to the $3^{\prime}$ position of the primers in human mtDNA (Anderson et al. 1981)
Regrettably, three nucleotides of the cytochrome $b$ sequence from the ray-finned fish Cichlasoma citrinellum were reported incorrectly in Fig. 2 of Meyer and Wilson (1990); they appear correctly in Meyer et al. (1990). These nucleotides are 1, 4, and 28 ; instead of C, A, C they should be A, C, G. Corrected nucleotides 1 and 4 remain phylogenetically uninformative, the correction of nucleotide 28 however adds another (the 17 th in cytochrome $b$ ) phylogenetically informative site in support of the lungfish-tetrapod sister group relationship.

\section{Results and Discussion}

Figure 2 shows the aligned DNA of the partial (up to $325 \mathrm{bp)} 12 \mathrm{~S}$ rRNA sequences. The alignment of the rRNA sequences is obvious for the first 245 base positions. After that the alignment becomes ambiguous so that phylogenetic analysis was confined to the first $245 \mathrm{bp}$. In this segment, positions varied by base substitutions and single base-pair additions or deletions. Thirty-five variable positions involved only transitional changes, 52 also transversions, and 6 additions or deletions were found.

Among closely related species transitions usually occur more frequently than transversions. There were six differences observed between the two African lungfish species, only one of which was a transversion. There were 40 differences between the South American and the African lungfishes, 19 of which were transversions. The frequency of transversions was higher than that of transitions when lungfishes were compared to the other groups, underscoring the antiquity of the split between the lineages. In 


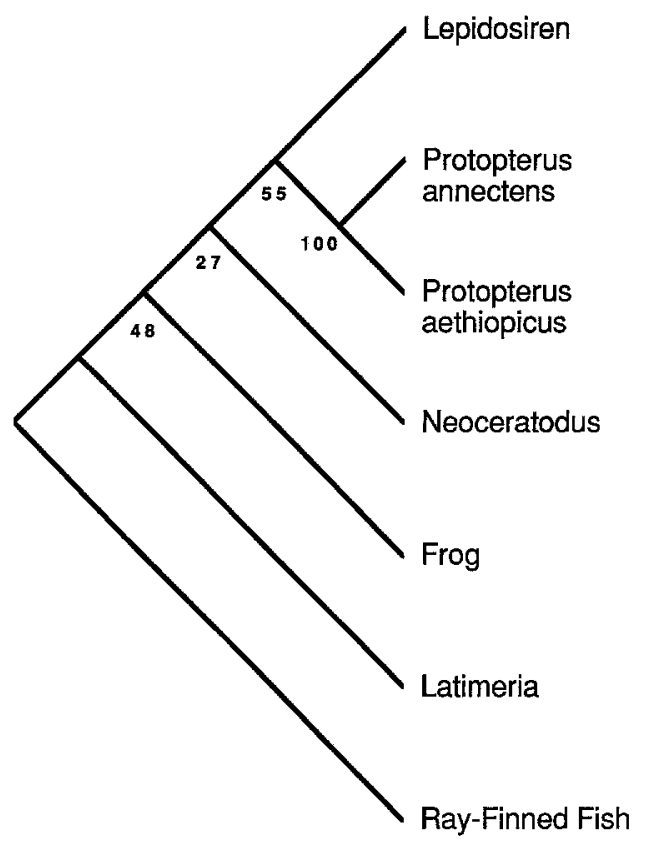

Fig. 3. Phylogenetic tree using transversion-parsimony analysis PAUP (version 3.0r $\beta 1$, Swofford 1991). Only the first 245bp aligned positions of $12 \mathrm{~S}$ rRNA were used in the analysis; the ray-finned fish was declared the outgroup. One shortest tree (TL $=73$ steps) was found. Numbers indicate percentage bootstrap values of 1000 replicates (Felsenstein 1985).

accordance with other studies (e.g., Miyamoto and Boyle 1989; Mindell and Honeycutt 1990), attention in the phylogenetic analysis was hence confined to transversions.

A parsimony analysis (exhaustive search option) (Swofford 1991) with the ray-finned fish as an outgroup was conducted. A single shortest tree was found (tree length $=73$, Fig. 3). This tree links the three lepidosirenid lungfishes Protopterus and Lepidosiren; their sister group is the Australian lungfish Neoceratodus. The lungfish clade is the sister group to the frog. The coelacanth was found to be the sister group to the lungfish-tetrapod clade. The inclusion of three species of two other lineages of lungfishes does not seem to contradict the earlier result of Meyer and Wilson (1990): lungfishes and not the coelacanth seem to be the closest living relatives of tetrapods.

The additional $12 \mathrm{~S}$ rRNA sequences support the finding, based on morphology (e.g., Marshall 1987; Schultze and Campbell 1987), that the two groups of lepidosirenid lungfishes (Protopterus and Lepidosiren) are more closely related to each other than to the Australian lungfish, Neoceratodus (Fig. 3). Furthermore, the new data seem to confirm (albeit weakly) that the lungfishes are a monophyletic group and are more closely related to the frog than is the coelacanth.

A bootstrap analysis (Felsenstein 1985) with 1000 replications using PAUP version 3.0r $\beta 1$ (Swofford
1991) favored the above-mentioned findings: (1) the joining of the lepidosirenid lungfishes and (2) the sister group relationship of the frog and lungfishes to the exclusion of the coelacanth (Fig. 3). However, the bootstrap values did not reach very high levels (Felsenstein 1985), making these results somewhat tentative. Obviously, the addition of two species of lungfish, while maintaining the overall pattern of relations, lowered the consistency index, as expected (Sanderson and Donoghue 1989).

More data will be needed to further test this phylogenetic hypothesis. We have already sequenced portions of the nuclear $18 \mathrm{~S}$ rRNA gene and several mitochondrial genes in some of these taxa (A. Meyer, unpublished). It is not clear whether these genes will be able to resolve the pattern of relations, however. The $18 \mathrm{~S}$ gene evolves too slowly and sporadically (see also Stock et al. 1991), and the 16S rRNA gene evolves too rapidly and shows much length variation that hinders optimal alignments. Longer portions of the mitochondrial 12S rRNA gene and sequences of nuclear and mitochondrial proteincoding genes seem to hold the greatest promise for providing data that might resolve this question with statistical confidence.

\section{Extinct and Extant Lobe-Finned Fishes and the Origin of Tetrapods}

The fossil record of actinopterygians and all groups of sarcopterygians goes back to a narrow window (about 30 million years wide) that dates back approximately 400 million years (Benton 1990). The virtually simultaneous occurrence of all the groups involved makes the question of the origin of tetrapods hard to answer based on the sequence of appearance of fossils.

Without a doubt, fossils are important in the reconstruction of phylogenies; this point has been made in an apt manner before (Gauthier et al. 1988; Donoghue et al. 1989). Fossils should even help to resolve the relationships among living taxa, because some fossils are likely to possess combinations of characters that are not present in any living taxon. Nevertheless, there is no denying that fossils have shortcomings as well. Most of the fossils are only available from incomplete skeletons and do not carry the same amount of information that can be found in recent forms. More characters for a cladistic analysis will always be found in recent taxa than in extinct ones. This fact (and others) has led to the observation that, in practice, fossils have not made much difference in the determination of branching patterns (Patterson 1981).

Often the fossil record is difficult to interpret, and the same features can be viewed differently by different researchers. Miles (1977) and Schultze (1987) both place much importance on the presence or ab- 
sence of cosmine and intracranial joints in sarcopterygian fishes, yet they reach radically different conclusions about the relationships of the groups under consideration and the evolution of these two characters. The history of tetrapods is particularly onerous because, as Miles (1977, p. 315) states, "no phylogeny of vertebrates can be perfectly parsimonious because of parallel and convergent evolution." A well-corroborated phylogeny is needed first in order to ask whether the morphological traits that were interpreted as synapomorphies of the lungfish-tetrapod clade really are synapomorphies or whether they represent homoplasies.

\section{Marshall and Schultze's Critique of Meyer and Wilson (1990)}

\section{Critique on Molecular Data and Analysis}

Marshall and Schultze (1992) reanalyzed the molecular data and confirmed that our data are robust and do not contain any obvious biases and that the phylogenetic analysis is sound. They confirm that the most parsimonious interpretation of the molecular data links lungfishes with tetrapods as sister groups to the exclusion of the coelacanth. Our data have also been reanalyzed and our conclusions confirmed by Forey (1991a). Also, the new sequences do not seem to contain any obvious base compositional biases that might influence phylogenetic inference (analysis not shown).

\section{Critique on Morphological Analysis} and Inferences

Based on the branching pattern established by our molecular data, we mapped morphological traits onto our phylogenetic tree (Meyer and Wilson 1990). Some of these traits were from soft tissues that are not preserved in fossils. The data were restricted to phylogenetically informative morphological traits present in all four extant groups under consideration, as they were the only ones that were available for molecular analysis.

Following the parsimony principle, Meyer and Wilson (1990) interpreted the inferred sharing of derived morphological characters in lungfish and tetrapods to mean that they are synapomorphies that arose (or were lost) along the $y z$ lineage (Fig. 1A). Of course, once the fossils are placed onto the tree, increasing the number of branches on the tree, this interpretation might have to be modified according to fossil evidence. Unfortunately, no consensus on the position of fossil groups that would have allowed us to securely incorporate paleontological data could be extracted from the paleontological literature. As indicated in our paper, the data in Table 2, compiled by P. Forey, were based exclusively on published sources (Rosen et al. 1981;
Lagios 1982; Forey 1987; Fritzsch 1987; Northcutt 1987; Schultze 1987). It is therefore not entirely obvious why Marshall and Schultze (1992) question us rather than the other eight authors from the primary literature upon which the data in Table 2 of Meyer and Wilson (1990) are based. Before we address Marshall and Schultze's (1992) critique on Meyer and Wilson's (1990) interpretation of the morphology of the living lobe-finned fishes trait by trait, we will first discuss a few general points.

\section{The Identity of the Closet Living Relative} of Tetrapods

Marshall and Schultze (1992) believe that Meyer and Wilson (1990) were misled in their interpretation of the morphology of living groups because they did not include fossils in their analysis. Several paleontologists believe that lungfish are the sister group of tetrapods even when fossils are considered (e.g., Rosen et al. 1981; Forey 1980; Gardiner 1980, 1984). Meyer and Wilson (1990) were aware that other paleontologists are skeptical of these results (e.g., Holmes 1985; Schultze 1987). This debate is still continuing among paleontologists.

Marshall and Schultze (1992, Fig. 3) present a branching pattern of living forms and fossils that is consistent with our molecular finding by placing lungfishes and not the coelacanth as the living sister group of tetrapods. Their favored phylogenies (Fig. $2 \mathrm{C}$ and D and Fig. 3 in their paper), however, include various fossil groups that separate lungfishes and tetrapods. They use this phylogeny (their Fig. 2C; Fig. 4B here) in their assertion that 13 out of 14 characters most parsimoniously interpreted to be synapomorphies by Meyer and Wilson (1990) are homoplasious. Obviously, for their interpretation to be correct (1) the branching pattern must be correct, and (2) the interpretation of character states in the fossils must be unambiguous. Neither seems to be established with a high degree of certainty. Moreover, the interpretation of character evolution of some morphological traits is quite different if their Fig. 2D is used as the "correct" phylogeny rather than their Fig. 2C.

Schultze has not always believed that the branching patterns presented in Fig. $2 \mathrm{C}$ and D or Fig. 3 of Marshall and Schultze (1992) or as Fig. 4B in this paper are the most parsimonious ones. Schultze (1987, p. 39) states "The dipnoans are not the closest sister group of tetrapods, independently if living forms only are considered, or fossil forms included." He maintains that a sister group relationship of dipnoans and tetrapods is "cladistically inappropriate" and that "the hypothetical common ancestor of the tetrapods and dipnoans is the common ancestor of all sarcopterygians" (p. 71). Figure 4A shows the branching pattern favored by Schultze in 1987 . He 
links the coelacanths and the extinct porolepiforms and osteolepiforms into the group crossopterygians and places lungfishes at the base of all lobe-finned fishes. Schultze's analysis includes morphological characters from fossils but excludes soft tissue characters because "they are unavailable in fossils" ( $p$. 69).

To the best of our knowledge, Schultze has not changed his interpretation of the fossil record, which he believes to indicate that coelacanths and not lungfish are the closest living relatives of tetrapods. Still, in 1991 (p. 191) Schultze states "actinistians can be considered as the closest living relatives of tetrapods." A critique by Schultze of Meyer and Wilson's (1990) character-state assignments with Latimeria as the closest living relative of tetrapods would have seemed to be more in line with Schultze's opinions. It would be illuminating to know explicitly which new data or which change in interpretation of old data led Schultze to such a drastic change of opinion regarding the relationships of sarcopterygians.

The Phylogenetic Position of Diabolepis and Other Crucial Fossils

Diabolepis speratus (Chang and $\mathrm{Yu} 1984$ ) is a species of fossil fish described on the basis of two fairly complete skulls, five anterior cranial portions, fragmentary tooth plates, and lower jaw rami. It is heralded to be one of the earliest lungfish fossils found so far. Marshall and Schultze (1992) place Diabolepis as the sister group to lungfishes in their Fig. 2C. Much of their argument about the homology of morphological traits depends on the reliability of the sister group relationship and character diagnosis of Diabolepis and lungfishes.

Some uncertainty surrounds the phylogenetic position of this species with respect to fossils and recent lungfishes: Schultze and Campbell (1987) state that the fossil is not well enough known "for definite statements about its relationship" (p. 25) and that (p. 37) all characters listed for Diabolepis as common with dipnoans "are questionable." Furthermore, they say "the evidence for considering Diabolepis as the sistergroup of the Dipnoi is weak" (p. 36). Campbell and Barwick (1987) suggest that "Diabolepis should be regarded as a modified 'crossopterygian' that shares no unique derived characters with primitive dipnoans" (p. 128). In 1991 Schultze (p. 191) still seems to be doubtful of the close relationship of Diabolepis with lungfishes but favors rather the view that Diabolepis more closely resembles primitive porolepiforms (like Youngolepis) than lungfishes.

Diabolepis and lungfishes are believed to be sister groups by Forey (1987). However, Forey differs in some aspects of the interpretation on the signifi-
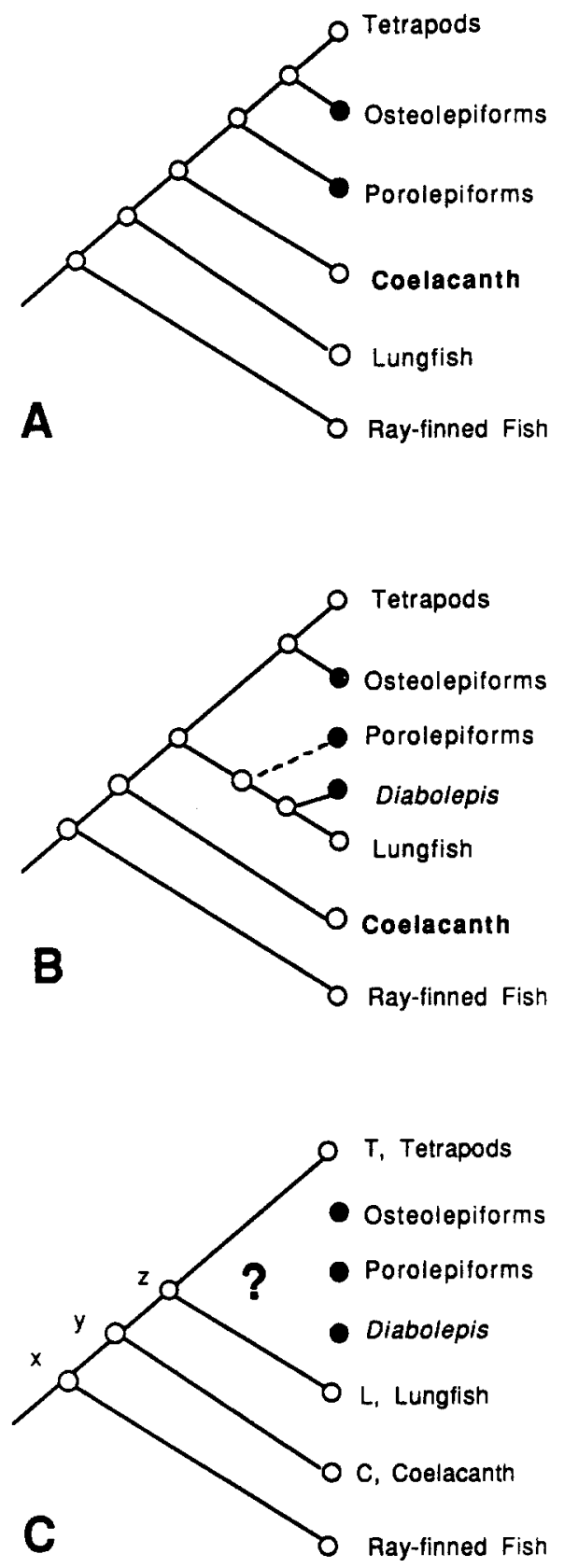

Fig. 4. A Phylogenetic relationship among the major sarcopterygian taxa according to Schultze (1987). Extinct groups under consideration (osteolepiforms, poroleptiforms, and Diabolepis) are marked with filled dots. B Phylogenetic relationship among the major sarcopterygian taxa according to Maisey (1986) used by Marshall and Schultze (1992) to argue that most of the 14 characters that have been interpreted to by synapomorphies of the lungfish-tetrapod clade (by Meyer and Wilson 1990) to be convergences. Stippled line indicates Maisey's (1986) suggestion (p. 232 and Fig. 12) that porolepiforms are not a monophyletic group and whose placement is uncertain in relation to Diabolepis and lungfishes. Note the inconsistencies between $\mathrm{A}$ and $\mathrm{B}$. The position of the coelacanth is highlighted. $C$ Diagram pointing out that the placement of the fossil groups is not certain.

cance of Diabolepis from Schultze (1987); he points out that it also shows an external nasal opening very close to the jaw and no external intracranial joint, which are features that Schultze and Arsenault (1985) 
use to link Panderichthys (an osteolepiform fish) and primitive amphibians. Forey $(1987$, p. 84) states "To this point in the essay I have discussed the introduction of lungfish fossils that have extended our knowledge of morphological variation to the extent that they have embraced characters formerly thought to be restricted to 'rhipidistians' and tetrapods. These fossils have therefore reduced the effectiveness of the traditional argument that places 'rhipidistians' as the sistergroup of tetrapods." However, this placement also means that some of the characters listed by Rosen et al. (1981) "may have arisen independently" (Forey 1987, p. 89). Maisey (1986) reviewed Diabolepis and several other fossils believed to be primitive dipnoans and suggested that several of these fossil forms are more closely related to extant dipnoans than Diabolepis and suggests that (p. 232) " 'porolepiforms' are really a paraphyletic group of "stem dipnoans.' "It appears that the discussion regarding the phylogenetic position of Diabolepis is not settled.

The exact assignment of fossils to lineages of early lungfishes is problematic(Miles 1977; Campbell and Barwick 1987; Marshall 1987). Marshall (1987) conducted the first cladistic study of this group that included a data matrix and used numerical analyses of traits. The results of his analysis differed in several respects from earlier studies. He brought his and the earlier results into agreement by abandoning some of the features of his cladogram, because he states "for theoretical and practical reasons, parsimony is not a good criterion for choosing between the possible phylogenies of dipnoans" (Marshall 1987, p. 151).

In the last 10-15 years a few new important fossils have been discovered that triggered some paleontologists to change their view about both the relationships of the living groups and also the question of the monophyly of the extinct group Rhipidistia. It is now widely believed that the Rhipidistia (formerly believed to be composed of porolepiforms and osteolepiforms) is not a natural group (Maisey 1986; Forey 1987). Porolepiforms and osteolepiforms had been closely allied to tetrapods by some paleontologists (e.g., Schultze 1987). Other paleontologists have linked lungfishes as the sister group to tetrapods to the exclusion of all extinct groups (e.g., Forey 1980, 1987; Gardiner 1980; Rosen et al. 1981). Panderichthys and Elpistostege are believed by some paleontologists to be intermediate between osteolepiform rhipidistians and tetrapods (e.g., Vorobjeva 1980; Schultze and Arsenault 1985).

Without the firmly established relationships of fossil and living forms it seems premature to try to trace single characters, because the interpretation of traits as synapomorphies (shared derived) or symplesiomorphies (shared primitive) or homoplasies depends on the branching pattern and has to be made post priori (though decisions about what character states are homologous are made a priori by character analysis). The decision about whether a particular character is due to recent common ancestry or convergent evolution can only be made in a phylogenetic context that takes all available information into consideration.

Trait-by-Trait Response to Marshall and Schultze's Critique

Quite often, a different interpretation and many opinions regarding the same fossil can be found in paleontology. Whether Marshall and Schultze (1992) or other paleontologists are correct in their reading of the fossils has to be decided in paleontological circles. We will simply furnish citations to provide alternative interpretations of character states. In the end we remain unconvinced that the placement of the fossils by Marshall and Schultze (1992) is strongly supported by a numerical cladistic analysis (Fig. 4C).

When Marshall and Schultze's (1992) revised character states and fossil taxa are included in a numerical cladistic analysis, the phylogeny that they claim they believe in (Fig. 4B) is not attained (data not shown). One has to assume that they have unlisted characters that support the branching pattern of Fig. 4B and outweigh the characters listed by Meyer and Wilson (1990) or their own reassigned character states for traits 1-14.

Trait 1: Internal Nostrils. Marshall and Schultze (1992) suggest that the internal nares evolved independently in lungfishes and tetrapods, because these structures are not homologous and not present in the putative sister group of lungfishes, Diabolepis. The homology of these structures between lungfishes and tetrapods had been questioned earlier by Holmes (1985) and Schultze (1987). Yet, Forey (1980, 1987) agrees with the other three authors of Rosen et al. (1981) in their interpretation of the internal nostrils as homologous structures (and synapomorphies) of lungfishes and tetrapods. Forey (1987) discusses the evidence for interpretation of the choanae of lungfishes and Diabolepis and tetrapods as a synapomorphy or parallelism and tentatively concludes (p. 87) "At present therefore I accept the choana as an homology specifying a group lungfishes and tetrapods."

Trait 2: Palate Fused with Neurocranium. Whether or not the fusion of the palate to the neurocranium is a synapomorphy of lungfish and tetrapods or a convergently evolved trait in these clades depends on the assumed phylogeny of the groups. Marshall and Schultze (1992) imply that the phylogeny (Fig. 
4B) is generally accepted. But Forey (1987), using a larger data set (he includes evidence from living taxa) than Schultze (1987), arrives at a drastically different phylogeny: one that links lungfish as sister group of tetrapods to the exclusion of all osteolepiforms.

Trait 3: Glottis. Marshall and Schultze (1992) assert that we only considered the morphology of a cichlid fish, as a representative of ray-finned fishes, when we assigned a character state to this trait. That is not so; the vast majority of all ray-finned fishes do not possess lungs. Primitive actinopterygian fishes like Amia, Lepisosteus, and Polypterus do posses lungs, whose homology to lungs of tetrapods is questionable. If lungs are present, some mechanism of closing the trachea must also be present. However, that mechanism and its ontogenetic derivation (therefore homology) can be quite different in different groups of organisms [e.g., the reptile and amphibian condition is quite distinct (Carl Gans, personal communication)]. Most importantly, the glottis and epiglottis are likely to be cartilaginous structures that would not be preserved in the fossil record and therefore would not be accessible to paleontological investigation. The repeated argument of Marshall and Schultze (1992) pointing out supposed differences between the two living groups of lungfish (Neoceratodus and lepidosirenid lungfishes) simply implies that in one of these lineages a trait has been lost or gained but does not detract from the fact that lungfishes are considered to be a natural group (Marshall 1987; Schultze and Campbell 1987).

Trait 4: Pharyngobranchial Gill Arch Elements. The pharyngobranchial gill arch elements are a set of bones that hold the gills necessary for aquatic respiration. These elements are reduced in recent lungfish and tetrapods. Most currently, Coates and Clark (1991) revised the ideas about the evolution of this trait (and trait 7, the hyomandibular bone) based on the fossil Acanthostega. Acanthostega, one of the earliest tetrapods known, has a full set of these elements. Its gill arch elements "resemble those of a Devonian lungfish such as Chirodipterus rather than the proximally narrow, bipartite ceratohyal and large hyomandibular bone of the Devonian osteolepiform Eusthenopteron" (Coates and Clark 1991, p. 234). These findings seem to support a sister group relationship between lungfishes and tetrapods to the exclusion of the osteolepiform Eusthenopteron (contra Schultze 1987). Such a phylogeny is not in concordance with the phylogeny shown in Fig. $2 \mathrm{C}$ and D of Marshall and Schultze (1992). Coates and Clark (1991) present other traits that link osteolepiforms with tetrapods to the exclusion of lungfishes, demonstrating that all evidence needs to be considered when branching orders are to be established. Once a most parsimonious solution is found, a posteriori character evolution can be traced back and a priori assumptions about character states being synapomorphies of a clade potentially can be revised based on this branching pattern.

Trait 5: Autopalatine Bone. Marshall and Schultze (1992) believe that this particular bone must have been present in Diabolepis, the putative sister group of lungfish, although that actual bone has not been found in the fossil (Chang and $\mathrm{Yu}$ 1984).

Trait 6: Depressor Mandibulae Muscle. This is a soft-tissue trait that is not available for study in fossil fishes. Bemis (1987) reports on the presence or absence of several muscles in the two groups of living lungfishes. It is not obvious how the presence of these muscles should make lepidosirenid lungfishes more terrestrially adapted than Neoceratodus. Of course, we are aware that lepidosirenid lungfishes are more adapted for terrestrial life than Neocerato$d u s$ but for reasons other than the depressor mandibulae. It is not apparant how the arguments of Marshall and Schultze (1992) that recent lungfish lineages differ in their adaptations to terrestrial life (given that both authors have argued that lungfishes are monophyletic) should have any bearing on the disputed interpretation of the cladistic status of the morphological traits.

Trait 7: Free Hyomandibular Bone. Marshall and Schultze's (1992) interpretation seems to differ from the findings of Coates and Clark (1991) and Rosen et al. (1981) (see above: trait 4).

Trait 8: Ethmoid Commissure Sensory Canal. The argument of Marshall and Schultze (1992)-repeated loss of his structure-would seem correct if the phylogeny (Fig. 4B) was shown to be supported by a thorough cladistic analysis.

Traits 9-12: Saccus Vasculosus of Pituitary Gland, Pars Nervosa of Pituitary Gland, Truncus Arteriosus of Heart, and Divided Auricle of Heart. None of these traits are preserved in fossils, and therefore character states of these traits in fossils are not available for study. Marshall and Schultze (1992) state that trait 10 is absent in Neoceratodus. It is not clear whether Lagios (1982) investigated the presence or absence of trait 10 in Neoceratodus. Burggren and Johansen (1987) studied traits 11 and 12 in detail, and small differences in the degree to which these traits are expressed exist. Lacking evidence to the contrary from fossils, all four traits currently have to be interpreted as synapomorphies of a lungfishtetrapod sister group. 
Traits 13 and 14: Limbs with More Than Four Mesomeres and Pelvic Girdles Joined. Marshall and Schultze (1992) dismiss these two traits as having evolved in parallel rather than being shared derived characters. Their argument again depends on the assumed phylogeny. Rosen et al. (1981) and Forey (1987) presented the morphological data on these two traits; their interpretation views them as synapomorphies of lungfish and tetrapods.

Further, Marshall and Schultze (1992) state that "The fossil record indicates that air breathing, and its associated physiological adaptations, arose independently in lungfish and tetrapods." They seem to include terrestrial locomotion as an associated physiological adaptation of air breathing because they dismiss traits 13 and 14 as parallelism based on their claim that air breathing "and its associated physiological adaptations" evolved independently in lungfish and tetrapods. It would seem that air breathing and terrestrial locomotion are two independent sets of characters. An air-breathing fish does not need to be adapted for terrestrial locomotion. A fish adapted for terrestrial locomotion does not have to be adapted for air breathing. A priori there is no reason to think that these character complexes should be coupled in any way.

\section{Toward a Resolution of the Origin of Tetrapods}

The contribution of molecular data is its ability to identify the lungfishes and not the coelacanths as the living sister group of tetrapods, a result that had not been agreed upon based on morphological data, although it had been suggested before (reviewed in Forey 1988). This conclusion (the branching pattern of Meyer and Wilson 1990) based on molecules may lead to an increased understanding of the morphological traits that might have preadapted the common ancestor of lungfishes and tetrapods to life on land. Obviously, the estimate of the common morphology of the ancestor of tetrapods would have looked differently had we found that the coelacanth and not the lungfishes is the closest living relative of the tetrapods. Once the attachment of the extinct lobe-finned fishes in a tree (Fig. 1A or 4C) on lineages (e.g., $z \mathrm{~T}, z \mathrm{~L}, x y$, or $y z$ ) is achieved, morphological changes can be ordered and reinterpreted cladistically. Knowledge of the sequence of morphological changes involved in the colonization of land might in this way be refined.

Character modification along a lineage may happen in all clades. To have legs is one of the character states that defines tetrapods. However, to have lost legs secondarily (as in snakes) does not make a difference in the assignment of snakes as tetrapods, as there are several other characteristics of snakes that clearly make them tetrapods. Similarly, even highly modified extant lungfishes can still be placed in the lungfish-tetrapod clade based on several morphological traits shared by all members of that clade. We argue that such traits are not always present in the fossils in question and that interpretations of fossils are contradictory. Hence support for particular trees based on paleontological data alone tend to be weak. Only paleontologists can decide, however, what common ancestors might have looked like, based on the interpretation of sister group relationships of living and extinct forms.

Traits will sort out in a way such that at the branch points of a phylogenetic tree the sister groups will end up with different assortments of novelties and plesiomorphic traits. Tetrapods did not pass through a point of "lungfishness." Both the lungfishes and tetrapod sister groups are derived from some sort of sarcopterygian fish with some traits that both lungfishes and tetrapods still have. This sorting out of traits along the $y z$ (Fig. 1A) lineage will occur all along that common lungfish-tetrapod lineage. If extinct groups did branch off this lineage, they will have some features that are characteristic of later lungfish and others shared with later tetrapods.

Phylogenetic trees are only statistical statements about genealogical relationships that are hopefully based on as many homologous characters as possible analyzed in a fashion that is logically acceptable (e.g., Cloutier 1991; Forey 1991b). Because characters can evolve repeatedly and be lost along a particular lineage, not all character states present at the terminal taxa of a tree will represent true synapomorphies but may be homoplasies. It is in this light that Meyer and Wilson (1990) made an assessment about the potential morphology of the common ancestor of lungfish and tetrapods, an ancestor they did not share with the coelacanth.

Some paleontologists explicitly ignore neontological data. Schultze's (1987) reasoning for this practice is that many traits present (e.g., soft traits that do not fossilize) in the living representatives are not found in the fossils or are likely to be modified from the ancestral lineages. This paleontological perspective seems to throw out most of the information that is obtainable. It seems unfounded to categorically ignore neontological data; all datapaleontological, neontological, and molecularshould be collected and analyzed in a manner that is open to criticism and checks.

A common practice in the paleontological literature is to simply list shared traits (presumed to be synapomorphies) on cladograms and neglect to conduct numerical analyses. Of course, only a rigorous numerical cladistic analysis including an outgroup (and explicit presentation of data in a matrix) will be able to identify which of the shared traits are 
derived. To establish a phylogeny for the extant lobe-finned fishes and fossils will require a careful cladistic analysis of all relevant taxa. This cladistic analysis should use all available forms of data including characters (soft anatomy and molecules) from the living members of lobe-finned fishes. It would seem an inappropriate practice to present arguments about relationships on a trait-by-trait basis without a final cladistic analysis that reveals synapomorphies and homoplasies. Without the presentation of a data matrix, a discussion is futile. Phylogenetic statements without a clear presentation of character states for all taxa under consideration are subjective statements that cannot be criticized and discussed.

Previously, Panchen and Smithson (1987) discussed many of the points made here. (1) Cladistic methodology is necessary for a solution to this problem. (2) Fossils will rarely be able to overturn a phylogeny that includes many more traits from living groups. (3) The interpretation of similarities in structures, if homologous, will have to be interpreted either as synapomorphic or as homoplasious; this decision depends on the most parsimonious phylogenetic estimate. (4) Many of the conclusions (about character state evolution but probably not branching order) depend on the study of early lungfish fossils, and whether or not these fossils can be assigned with any certainty to belong to the lungfish lineage or to other lineages.

We agree with Schultze (1991, p. 111) who states, "we will see a continuing discussion over the relationships of sarcopterygians in the future."

Acknowledgments. For discussion and comments we thank Mike Bell, Max Hecht, Ellen Prager, David Reznick, Robert Sokal, David Wake, and Paul Wilson. Our manuscript was also critically read and improved by Charles Marshall and Hans-Peter Schultze. Allan C. Wilson provided support (through NSF and NIH), advice, inspiration, and insights during the initial part of this work. Tissues were kindly provided by David Reznick (Lepidosiren), Robert Murphy (Latimeria), and William Bemis and Richard Sage (Protopterus). Blair Hedges and Linda Maxson determined the sequence for Neoceratodus reported here and kindly provided it for this paper. This work received partial support (to A.M.) from the Systematic Biology Section of NSF (BSR-9107838 and BSR-9119867). The sequences reported have been deposited in GenBank (accession nos. M87532-M87537).

\section{References}

Anderson S, Bankier AT, Barrell BG, de Bruijn MHL, Coulson AR, Drouin J, Eperon IC, Nierlich DP, Roe BA, Sanger F, Schreier PH, Smith AJH, Staden R, Young IG (1981) Sequence and organization of the human mitochondrial genome. Nature 290:457-465

Bemis WE (1987) Feeding systems of living dipnoi: anatomy and function. J Morphol Suppl 1:249-275

Benton MJ (1990) Phylogeny of the major tetrapod groups: morphological data and divergence dates. J Mol Evol 30:409_ 424

Burggren WW, Johansen K (1987) Circulation and respiration in lungfishes (Dipnoi). J Morphol Suppl 1:217-236

Campbell KSW, Barwick RE (1987) Paleozoic lungfishes-a review. J Morphol Suppl 1:93-131

Chang MM, Yu X (1984) Structure and phylogenetic significance of Diabolichthys speratus gen. et sp. nov., a new dipnoan-like form from the Lower Devonian of eastern Yunnan, China. Proc Linn Soc NSW 107:171-184

Cloutier R (1991) Patterns, trends, and rates of evolution within the Actinistia. In: Musick JA, Bruton MN, Balon EK (eds) The biology of Latimeria chalumnae and evolution of coelacanths. Kluwer, Hingham MA, pp 23-58

Coates MI, Clark JA (1991) Fish-like gills and breathing in the earliest known tetrapod. Nature 352:234-236

Donoghue MJ, Doyle JA, Gauthier J, Kluge AG, Rowe T (1989) The importance of fossils in phylogenetic reconstruction. Annu Rev Ecol Syst 20:431-460

Felsenstein J (1985) Confidence limits on phylogenies: an approach using the bootstrap. Evolution 39:783-791

Forey PL (1980) Latimeria: a paradoxical fish. Proc R Soc Lond B 208:369-308

Forey PL (1987) Relationships of lungfishes. J Morphol Suppl $1: 75-91$

Forey Pl (1988) Golden jubilee for the coelacanth Latimeria chalumnae. Nature 336:727-732

Forey PL (1991a) Blood lines of the coelacanth. Nature 351: 347-348

Forey PL (1991b) Latimeria chalumnae and its pedigree. In: Musick JA, Bruton MN, Balon EK (eds) The biology of Latimeria chalumnae and evolution of coelacanths. Kluwer, Hingham MA, pp 75-97

Fritzsch B (1987) Inner ear of the coelacanth fish Latimeria has tetrapod affinities. Nature 327:153-154

Gardiner BG (1980) Tetrapod ancestry: a reappraisal. In: Panchen AL (ed) The terrestrial environment and the origin of land vertebrates. Academic Press, New York, pp 177-185

Gardiner BG (1984) The relationships of the palaeomiscid fishes, a review based on new specimens of Mimia and Moythomasia from the Upper Devonian of western Australia. Bull Br Mus Nat Hist Geol 37:173-428

Gauthier J, Kluge AG, Rowe T (1988) Amniote phylogeny and the importance of fossils. Cladistics 4:105-209

Gee H (1990) Fossil fishes and fashion. Nature 348:194-195

Gorr T, Kleinschmidt T, Fricke H (1991) Close tetrapod relationships of the coelacanth Latimeria indicated by haemoglobin sequences. Nature 351:394-397

Hedges BS, Moberg KD, LR Maxson (1990) Tetrapod phylogeny inferred from $18 \mathrm{~S}$ and $28 \mathrm{~S}$ ribosomal RNA sequences and a review of the evidence for amniote relationships. Mol Biol Evol 7:607-633

Hillis DM, Dixon MT (1989) Vertebrate phylogeny: evidence from $28 \mathrm{~S}$ ribosomal DNA sequences. In: Fernholm B, Bremer $\mathrm{K}$, Jornvall $\mathbf{H}$ (eds) The hierarchy of life. Elsevier, Amsterdam, pp 355-367

Holmes EB (1985) Are lungfishes the sister group of tetrapods? Biol J Linn Soc 25:379-397

Kocher TD, Thomas WK, Meyer A, Edwards SV, Paabo S, Villablanca FX, Wilson AC (1989) Dynamics of mitochondrial DNA evolution in animals: amplification and sequencing with conserved primers. Proc Natl Acad Sci USA 86:6196-6200

Lagios MD (1982) Latimeria and the Chondrichthyes as sister taxa. Copeia 1982:942-948

Lovtrup S (1977) The phylogeny of vertebrata. Wiley, London

Maeda N, Zhu D, Fitch WM (1984) Amino acid sequences of lower vertebrate parvalbumins and their evolution. Mol Biol Evol 1:473-488 
Maisey JG (1986) Heads and tails: a chordate phylogeny. Cladistics 2:201-256

Marshall CR (1987) Lungfish: phylogeny and parsimony. J Morphol Suppl 1:151-162

Marshall CR, Schultze H-P (1992) Relative importance of molecular, neontological and paleontological data in understanding the biology of the vertebrate invasion of land. J Mol Evol 34:93-101

Meyer A, Wilson AC (1990) Origin of tetrapods inferred from their mitochondrial DNA affiliation to lungfish. J Mol Evol 31:359-364

Meyer A, Wilson AC (1991) Coelacanth's relationships. Nature 353:219

Meyer A, Kocher TD, Basasibwaki P, Wilson AC (1990) Monophyletic origin of Lake Victoria cichlid fishes suggested by mitochondrial DNA sequences. Nature 347:550-553

Miles RS (1977) Dipnoan (lungfish) skulls and the relationships of the group: a study based on new species from the Devonian of Australia. Zool J Linn Soc 61:1-328

Mindell DP, Honeycutt RL (1990) Ribosomal RNA in vertebrates: evolution and phylogenetic applications. Annu Rev Ecol Syst 21:541-566

Miyamoto MM, Boyle SM (1989) The potential importance of mitochondrial DNA sequence data to eutherian mammal phylogeny. In: Fernholm B, Bremer K, Jornvall H (eds) The hierarchy of life. Elsevier, Amsterdam, pp 437-450

Normark BB, McCune AR, Harrison RG (1991) Phylogenetic relationships of neopterygian fishes, inferred from mitochondrial DNA sequences. Mol Biol Evol 8:819-834

Northcutt RG (1987) Lungfish neural characters and their bearing on sarcopterygian phylogeny. J Morphol Suppl 1:277-297

Panchen AL, Smithson TR (1987) Character diagnosis, fossils and the origin of tetrapods. Biol Rev $62: 341-438$

Patterson C (1980) Origin of tetrapods: historical introduction to the problem. In: Panchen AL (ed) The terrestrial environment and the origin of land vertebrates. Academic Press, New York, pp 159-175

Patterson C (1981) Significance of fossils in determining evolutionary relationships. Annu Rev Ecol Syst 12:195-223

Roe BA, Ma D-P, Wilson RK, Wong JF-H (1985) The complete nucleotide sequence of the Xenopus laevis mitochondrial genome. J Biol Chem 260:9759-9774

Romer AS (1966) Vertebrate paleontology, ed 3. University of Chicago Press, Chicago
Rosen DE, Forey PL, Gardiner BG, Patterson C (1981) Lungfishes, tetrapods, paleontology, and plesiomorphy. Bull Am Mus Nat Hist 167:159-276

Sanderson MJ, Donoghue MJ (1989) Patterns of variation in levels of homoplasy. Evolution 43:1781-1795

Schultze H-P (1987) Dipnoans as sarcopterygians. J Morphol Suppl 1:39-74

Schultze H-P (1991) CT scan reconstruction of the palate region of Latimeria chalumnae. In: Musick JA, Bruton MN, Balon EK (eds) The biology of Latimeria chalumnae and evolution of coelacanths. Kluwer, Hingham MA, pp 183-192

Schultze H-P, Arsenault M (1985) The panderichthyid fish $E l$ pistostege: a close relative of tetrapods? Palaeontology 28 : 293-309

Schultze H-P, Campbell KSW (1987) Characterization of the Dipnoi, a monophyletic group. J Morphol Suppl 1:25-37

Sharp PM, Lloyd AT, Higgins DG (1991) Coelacanth's relationships. Nature 353:218-219

Smith JLB (1939) A surviving fish of the order Actinistia. Nature 143:455-456

Smith JLB (1953) The second coelacanth. Nature 171:99-101

Stock D, Moberg KD, Maxson LR, Whitt GS (1991) A phylogenetic analysis of the $18 \mathrm{~S}$ ribosomal RNA sequence of the coelacanth Latimeria chalumnae. In: Musick JA, Bruton MN, Balon EK (eds) The biology of Latimeria chalumnae and evolution of coelacanths. Kluwer, Hingham MA, pp 99-117

Stock DW, Swofford DL (1991) Coelacanth's relationships. Nature 353:217-218

Swofford DL (1991) PAUP: phylogenetic analysis using parsimony, version 3.0rB1. Illinois Natural History Survey, Champaign IL

Thomson KS (1991) Living fossil: the story of the coelacanth. Norton, New York

Vorobjeva EI (1980) Observations on two rhipidistian fishes from the Upper Devonian of Lode, Latvia (Lode). Zool J Linn Soc 70:191-201

Wahlert G von (1968) Latimeria und die Geschichte der Wirbeltiere. Fischer, Stuttgart, West Germany

Wiley EO (1979) Ventral gill arch muscles and the interrelationships of gnathostomes, with a new classification of the Vertebrata. Zool J Linn Soc 67:149-179

Received November 11, 1991/Revised and accepted April 6, 1992 